\title{
A Journey To Triumph: The Making Of THRICE Project Using Oracle Technology
}

Nor Farzana Abd Ghani, Universiti Utara Malaysia, Malaysia

Ku Ruhana Ku Mahamud, Universiti Utara Malaysia, Malaysia Maznah Mat Kasim, Universiti Utara Malaysia, Malaysia

Fader Abdullah, Universiti Teknologi MARA, Malaysia

\begin{abstract}
THRICE project is kicking off in February 2010, to integrate all learning systems built from the previous projects; namely, Sekolahku.net, online training solution for Malaysia's Institute for Accountancy and online training solution for Technology Park Malaysia College. All projects are owned by In-Fusion Solutions Sdn. Bhd. and are e-learning solutions, which support its core business. THRICE project will mainly leverage on the Oracle as its main technology. Integrating to new technology may not be as good as it sounds because some issues need to be considered in terms of making sure the transition process to Oracle run smoothly. Apart from that, the mobilization of staff needs to be decided in making sure THRICE project becomes a success in fulfilling the client's wish.
\end{abstract}

Keywords: E-learning Technology Integration; MOSS; Oracle SOA Technology

\section{INTRODUCTION}

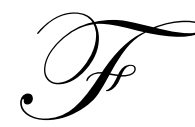

usionware Systems Private Limited is a joint venture between Twiceware Solutions Private Limited (India) and In-Fusion Solutions Sdn. Bhd (ISSB) of Malaysia's In-Fusion Group. It is the technology solutions wing of TWICE group of companies. TWICE group was founded in 2003 as Twiceware Solutions Private Limited, is committed to providing practical and effective solutions in areas of eLearning, Multimedia and Knowledge Services. Fusionware is set to provide education acceleration services that, in the future, would change the way education is approached and delivered the world over today. The company provides services that enable enterprise knowledge management for universities, colleges, schools and corporate organizations. Most projects undertaken by Fusionware in the earlier years were to support the TWICE group itself, as well as external projects in India, and was determined to set global footprints in the US, UK, Malaysia and Singapore.

Twiceware's strengths are in both Microsoft Office SharePoint Server 2007 (MOSS) and Oracle Service Oriented Architecture (SOA). As an education solution and services provider, ISSB's core products include courseware, enterprise resource planning (ERP) system for the education environment, educational games, Learning Content Management System, Student Information Management System, Integrated Campus Management System, Islamic Banking and Finance Program, Knowledge Information Exchange System and Portal experience.

ISSB recognizes the emergence of both MOSS and Oracle SOA as very important tools used in the development of applications today and the demand for personnel in both of these skills. Fusionware which will be the global software centre for both groups and their clients in application development using MOSS and Oracle SOA and will address the lack of such skills in Malaysia. It will also be the catalyst that will allow In-Fusion Solutions to grow beyond its core competency in the education industry to others, such as banking, telecommunication, healthcare and manufacturing.

Having successfully delivered the best education solutions to its clients, ISSB foresees the challenge to provide a complete spectrum of solutions to enhance learning experience and administration of virtual learning. The main highlight for 2010 is to integrate the management of learning content, learning activities and student data into 
one suite of products and, at the same time, give flexibility to future clients to customize the product according to their needs.

\section{BACKGROUND}

Fusionware Systems Private Limited is as a Joint Venture between Twiceware Solutions Private Limited (India) and In-Fusion Solutions Sdn. Bhd of Malaysia's In-Fusion Group. Founded in 2003, In-Fusion Solutions Sdn. Bhd is committed to providing practical and effective solutions in areas of eLearning, Multimedia and Knowledge Services. The joint venture between the two companies was made in March 2008 to leverage Twiceware's strength in solution development. Prasadh M.S was appointed as the Executive Director and Selvakumar Baalu as the Managing Director and CEO. Fusionware is set to provide education acceleration services that in the future would change the way education is approached and delivered world over today.

ISSB and Twiceware collaborate to provide schools with a dynamic enterprise learning management system. Learning Management System is an application that delivers, manages, tracks and reports all interactions of e-learning. Fusionware's advanced LMS automates student registration, tracks learner progress, and records test scores that indicate course completion. This online learning and management system enables trainers to assess the performance of their students.

With more than six years' of experience from Twiceware and highly skilled professionals, the company is currently collaborating with some of the world's leading organizations to solve their most complex and critical IT infrastructure, applications and business process outsourcing needs.

\section{Technology Expertise}

Fusionware continuously undertakes a comprehensive technology scan to evaluate the possible impact of new and emerging technologies on its clients' businesses. However, Fusionware considers MOSS and Oracle Fusion Middleware as their main profiles. Table 1 below provides a brief overview of Fusionware overall technical skill set:

Table 1: Fusionware's Area of Expertise

\begin{tabular}{|c|c|}
\hline Area & 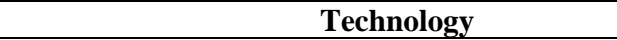 \\
\hline Programming & $\begin{array}{ll}- & \text { Java, JS } \\
\text { - } & \text { JSP, ASP, ASP.NET } \\
\text { - } & \text { C, C++, C\# } \\
\text { - } & \text { VBScript } \\
\text { - } & \text { XML, XSL, XSLT } \\
\text { - } & \text { Perl, PHP, CGI } \\
\text { - } & \text { SQL/PLSQL } \\
\text { - } & \text { HTML / DHTML } \\
\end{array}$ \\
\hline RDBMS & $\begin{array}{ll} & \text { Oracle } \\
- & \text { MS-SQL } \\
\text { - } & \text { MYSQL } \\
\end{array}$ \\
\hline Middleware & $\begin{array}{ll}\text { - } & \text { Oracle Fusion Middleware } \\
\text { - } & \text { TIBCO }\end{array}$ \\
\hline Platform & $\begin{array}{ll}- & \text { NET } \\
- & \text { JavaEE } \\
\end{array}$ \\
\hline Portal Solutions & - $\quad$ MS Office SharePoint Server 2007 \\
\hline $3^{\text {rd }}$ Party Tool Integration & $\begin{array}{ll}\text { - } & \text { Intelliview Data Analysis Tool - Synaptris } \\
\text { - } & \text { Fusion Charts - InfoSoft Global } \\
\end{array}$ \\
\hline
\end{tabular}

Having chosen MOSS services as their flagship offering, the company is focused to: 1) hire additional development and consulting resources with a minimum industry Microsoft Sharepoint experience of three years, 2) ensure necessary individual certifications and renewals for all team resources, 3) obtain Microsoft enrolments and 
partner certifications for the organization, and 4) participate in all MOSS events and forums for networking and exposure. Currently, the company has four MOSS certified engineers to help with solution development (Exhibit 1).

\section{Projects}

Challenges faced by Fusionware as a budding software house are undeniable. For the first three months of its operation, all jobs completed were only from the group itself, Twiceware. The projects are crucial to support the backbone operation of most companies under TWICE group. Nevertheless, Fusionware believes that by embarking on a few small projects in the beginning, soon their reputation will be established locally and internationally.

Fusionware has all what it takes to fulfill the need for education of adults, top executives, young children and higher institution learners. Exhibit 2 presents a list of all projects' details granted to Fusionware as of December 2009. Fusionware, together with In-Fusion Solutions, is collaborating on three major projects; namely, Sekolahku.NET, MIA and TPM College.

\section{TECHNOLOGY FOR THRICE}

THRICE project was an idea from Dr. Mohamad Salmi Mohd Sohod, the owner of ISSB. There are three main solutions under THRICE; namely, StudentSpace, LearnSpace and ContentSpace (Exhibits 3, 4 and 5). The three solutions will be built module-by-module to accommodate the client's needs should any customization be required. The idea is to integrate all three solutions so it can provide a complete spectrum of solutions to enhance learning experience and administration of virtual learning. Other systems also included in the THRICE product consist of the Online Tutorial System and Question Bank System.

THRICE product is using the 'Software as a Service' (SaaS) model, whereby a product that is hosted by a provider licenses an application to customers for use as a service on demand. The clients, in this case, can be the organizations and individuals. Three projects have been identified to be integrated into THRICE's suite of products. The projects are solutions that Fusionware has been concentrating on since the beginning of the joint venture with ISSB. Sekolahku.Net, scheduled to kick off in June 2010, is developed using .NET platform, MOSS 2007 and SQL 2005. MIA's and TPM College's online training solutions were completed in September 2009 and April 2009 respectively. They utilized JavaEE and Velocity Framework technologies (Exhibit 2).

The client will be able to subscribe to solutions together or by individual applications. To control the usage and billing of the services by respective clients, a billing system will be created to evaluate the subscription rates accordingly and send automatic alerts to clients when their subscription has ended. In terms of administrating the operations of THRICE, an Administration System will be put in place onto the above modules and will act as a filter or a security for the customers' data. This module typically filters out the data of different customers so that the customers could see only the data which belongs to them. Moreover, this module works in tandem with the billing module and the rest of the applications. This module is internally used by the client to maintain the users (create ids and grant access to them). The high level architecture diagram of the THRICE is shown in Exhibit 6.

The Oracle server contains the web modules and web services that are connected to all database servers. The Oracle BPEL (Business Process Execution Language) is used to define the work flow and the business execution sequence; for example, the creation of customers and customer ID, sending alerts, etc. By using a centralized Oracle server, the entire application is controlled by the customer ID; hence, the data integrity of the customer is achieved. The data is never duplicated in any of the databases. For example, the customer data never resides in any of the MySQL databases, except in the Oracle database. This eliminates data redundancy in the system, making it more responsive and cost less on the storage. All systems that require customer data will talk to the Oracle database to get the details. This concept confines the SOA standards.

\section{THE MEN BEHIND FUSIONWARE}

Current practice in Fusionware for managing its resources is to be efficient and productive as much as possible. In light of the current economic situation whereby the company needs to be small and manageable, 
according to designated projects, there are only around 10 employees involved with Fusionware, according to designated projects. T. Hemanth Raman plays the role as the Project Lead cum Head of Fusionware. Currently only five staff members are experts in Oracle; a team is led by Hemanth himself. The rest of the staff members are experts in .Net. Together both teams support each other according to dedicated projects. Each staff is allocated to one particular project at one time. The team's working standard operating procedure is to finish the development of the solution first and then try to concentrate on the documentation.

Project progress, milestones and man-hours spent are monitored by simple timesheets and Microsoft projects. Every staff in required to fill in a timesheet and submit it on a weekly basis. Man-hours consist of two types - non-billable and billable. Controlling the cost of man-hours of any given project is also important as it is relatively cheap to use OSS technology compared to using Oracle and MOSS technologies.

Following the trend of any software house, the majority of Fusionware's staff members are still young (below 32 years of age). Looking at the dynamicity of the industry, hence, the staff has a tendency to look for better opportunities from other IT companies, both locally and internationally. The competition of the IT companies to hire good programmers and fulfill the set of skills necessary to become fluent in certain technology is becoming obvious in the past few years. Indian IT workers are not cheap anymore and are highly demanded outside India, as well as locally.

\section{FULFILLING CLIENTS' REQUIREMENT}

Fusionware is aware of a difference of language, culture, time and distance between clients in Malaysia and the developer team in India. Nevertheless, the time and distance gaps are narrowing down as the emergence of Internet technology offers applications, such as Email, Instant Messaging and Voice over Internet Protocol (VoIP), which makes communication between them free and easy. In every project, the development of the solution starts with the proof of concept $(\mathrm{PoC})$. PoC is developed first before it is presented to the clients. The development process is conducted iteratively, until the client is satisfied with the solution,

In some cases, travel is required to Malaysia to physically meet with the clients to enhance understanding of the requirements. In any project, scope creep is a common problem. Uncontrolled changes in a project's scope are unavoidable and need to be handled properly by the team. In addition, language and culture barriers also create a misunderstanding of the requirements. The team usually has a list of milestones, or a 'Term of References' document that is agreed upon by both parties to minimize scope creep. Once a project is completed, Fusionware will station help desk personnel in ISSB to handle bugs and provide other support to their clients.

\section{SUMMARY}

By January 2010, Fusionware will be considered matured enough to 'hatch' from the incubator, which means Fusionware can no longer depend on the support from TWICE group. It is a challenging year ahead for Fusionware as plans to make its presence outside of India is on the way. THRICE project will be an ultimate test for Fusionware to prove to TWICE group that they are finally ready to fly on their own after being dependent on the group's support for almost two years.

As Hemanth and his team scrutinize the plan for the THRICE project in December 2009, some issues need to be considered to ensure the smooth transition into Oracle technology - the mobilization of staff for THRICE project and, at the same time, to ensure that the client's requirements are fulfilled. Kicking off in February or March 2010, the THRICE project will be the main focus before Fusionware can start contemplating expanding themselves to Australia, UK and US in the coming years. 


\section{AUTHOR INFORMATION}

Nor Farzana Abd Ghani was a Universiti Utara Malaysia graduate in 2002 where she earned a Bachelor in Information Technology. She also received a Master in Information Technology, specializing in Database Management System from the University of Sydney in 2005. Her career goal changed from working as a junior consultant in an ICT consulting firm based in MSC Cyberjaya, Malaysia to being a budding academic in Universiti Utara Malaysia since 2006. Her research interests include project management, e-commerce website evaluation, bridging digital divide and e-inclusion.

Prof. Dr. Ku Ruhana Ku Mahamud holds a Bachelor degree in Mathematical Sciences and a Master degree in Computing, both from Bradford University, UK in 1983 and 1986, respectively. Her PhD in Computer Science was obtained from Universiti Pertanian Malaysia in 1993. As an academic at the Universiti Utara Malaysia since 1984, her research interests include computer systems performance modeling, ant colony optimization and intelligent agent. These and other works have been published in international and national journals, proceedings of international conferences and other publications. Her book on ' $\mathrm{C}$ Programming' has won her the best publication award in the academic book category in 1999 and in 2002, she published another academic book on "Mathematics for Business'.

Dr. Maznah Mat Kasim earned a Bachelor degree and Master degree in Mathematics from Wichita State University, USA in 1984 and 1986 respectively. Her PhD is in Operational Research was obtained in 2008 from Universiti Kebangsaan Malaysia. As an academic at Universiti Utara Malaysia, her research interests are multicriteria decision making, and performance measurement.

Fader Abdullah received a Bachelor degree in Economics from Universiti Malaya and a Master degree in Business Administration from Universiti Utara Malaysia in 1983 and 2001 respectively. He is currently a lecturer at the Faculty of Business in Universiti Teknologi MARA since 2002. Mr Fader had 15 years of experience working in a commercial bank and his last position was a branch manager. As an academic, his research interests include strategic management, international business and entrepreneurship.

\section{REFERENCES}

1. Fusionware Systems (2008). About Fusionware Systems Private Limited. Retrieved January 5, 2010 from http://fusionware.co.in/overview.html

2. In-Fusion Solutions Sdn Bhd (2008). About In-Fusion Solutions Sdn Bhd. Retrieved January 15, 2010 from http://www.in-fusion.com.my/in-fusion/c/About\%20Us

3. $\quad$ Price and Waite (2008) "Oracle Forms to SOA: A Case Study in Modernization"

4. Spinello, R. A. (1997). Case Studies in Information and Computer Ethics, New Jersey: Prentice Hall.

5. Varma, R. and Rogers, E.M. (2004). "Indian Cyber Workers in US". Economic and Political Weekly. 


\section{EXHIBIT 1 - MICROSOFT OFFICE SHAREPOINT SERVER 2007}

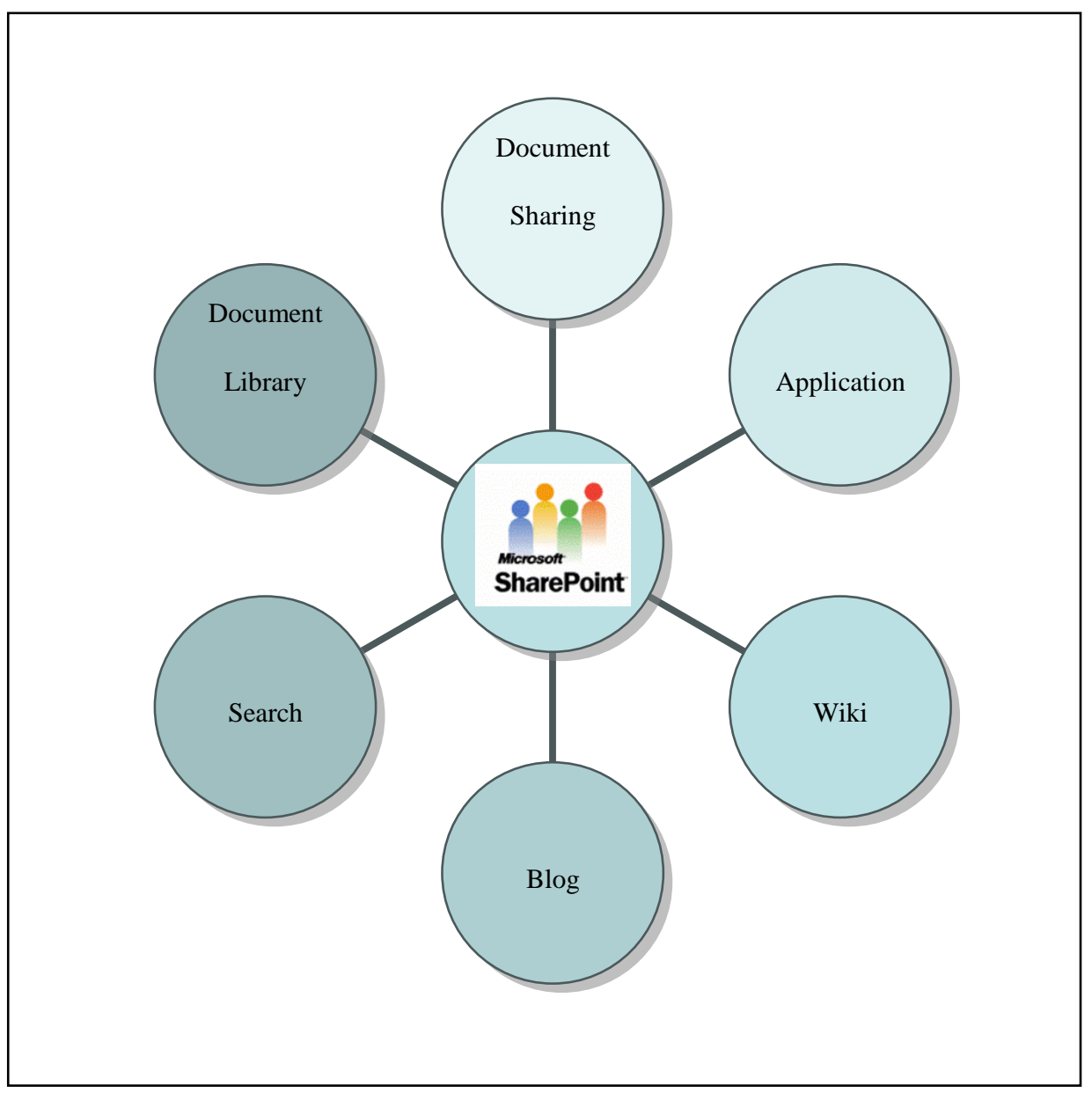

Microsoft Office SharePoint 2007 is a new server program that is part of the 2007 Microsoft Office system. Organizations can use MOSS to facilitate collaboration through:

1. Content management

2. Implement Business Processes \& Work Flow Management

3. Document and File Sharing

4. Privileged information access by department 


\section{EXHIBIT 2 - FUSIONWARE PROJECTS}

\begin{tabular}{|c|c|c|c|c|c|}
\hline Project & Status & Client & Technology & Start Date & End Date \\
\hline THRICE & - & ISSB & - Oracle & $2 / 2010$ & - \\
\hline $\begin{array}{l}\text { Sekolahku.Net } \\
\text { - E-Mentor } \\
\text { - Question Bank }\end{array}$ & $\begin{array}{l}90 \% \\
10 \%\end{array}$ & ISSB & $\begin{array}{l}\text { - } \text {.NET } \\
\text { - MOSS } 2007 \\
\text { - MySQL } 2005\end{array}$ & $3 / 2008$ & $6 / 2010$ \\
\hline $\begin{array}{l}\text { TwiceImage: Invoice } \\
\text { Maintenance }\end{array}$ & - & $\begin{array}{l}\text { Internal (TWICE } \\
\text { Group) }\end{array}$ & $\begin{array}{l}\text { - } \text {.NET } \\
\text { - MySQL } 2000\end{array}$ & \multicolumn{2}{|l|}{ Ongoing } \\
\hline MOODLE LMS & - & - & $\begin{array}{l}\text { - Open Source Software } \\
\text { - MySQL }\end{array}$ & \multicolumn{2}{|l|}{ Ongoing } \\
\hline OKJ CRM & $100 \%$ & $\begin{array}{l}\text { External } \\
\text { (Chennai) }\end{array}$ & $\begin{array}{l}\text { - } \text {.NET } \\
\text { - MySQL } 2005\end{array}$ & $10 / 2009$ & $01 / 2010$ \\
\hline Wi-MEXX & $100 \%$ & $\begin{array}{l}\text { External } \\
\text { (Hong Kong) }\end{array}$ & $\begin{array}{l}\text { - . NET compact } \\
\text { - Framework 2.0/XML }\end{array}$ & $5 / 2009$ & $12 / 2009$ \\
\hline MIA & $100 \%$ & ISSB & $\begin{array}{l}\text { - JavaEE } \\
\text { - Velocity Framework }\end{array}$ & $7 / 2009$ & $9 / 2009$ \\
\hline Twicestore & $100 \%$ & $\begin{array}{l}\text { Internal (TWICE } \\
\text { Group) }\end{array}$ & $\begin{array}{l}\text { - } \text {.NET } \\
\text { - MySQL } 2005\end{array}$ & $2 / 2009$ & $4 / 2009$ \\
\hline TPM College & $100 \%$ & ISSB & $\begin{array}{l}\text { - JavaEE } \\
\text { - Velocity Framework }\end{array}$ & $8 / 2008$ & $4 / 2009$ \\
\hline ORANGE HRM & $100 \%$ & - & $\begin{array}{l}\text { - Open Source Software } \\
\text { - MySQL }\end{array}$ & $8 / 2008$ & $9 / 2008$ \\
\hline Maya Motors & $100 \%$ & $\begin{array}{l}\text { Internal (TWICE } \\
\text { Group) }\end{array}$ & $\begin{array}{l}\text { - } \text {.NET } \\
\text { - MySQL } 2005\end{array}$ & $4 / 2008$ & $6 / 2008$ \\
\hline $\begin{array}{l}\text { Safe Infratech: } \\
\text { Invoicing System }\end{array}$ & $100 \%$ & $\begin{array}{l}\text { Internal (TWICE } \\
\text { Group) }\end{array}$ & $\begin{array}{ll}\text { - } & \text {.NET } \\
\text { - } & \text { MySQL } 2000\end{array}$ & $4 / 2008$ & $5 / 2008$ \\
\hline SUGAR CRM & $100 \%$ & - & $\begin{array}{l}\text { - Open Source Software } \\
\text { - MySQL }\end{array}$ & $3 / 2008$ & $4 / 2008$ \\
\hline BAMBOO INVOICE & $100 \%$ & - & $\begin{array}{l}\text { - Open Source Software } \\
\text { - MySQL }\end{array}$ & $3 / 2008$ & $4 / 2008$ \\
\hline
\end{tabular}

\section{EXHIBIT 3 - STUDENTSPACE}

\section{STUDENTSPACE - Innovative Learning}

Student Information System, STUDENTSPACE, is a Web-based self-service environment for educational establishments to manage student data. STUDENTSPACE provides capabilities for entering student test and other assessment scores, building student schedules, tracking student attendance, and managing many other studentrelated data needs in a school, college or university. STUDENTSPACE is an Integrated Software Package. It is a data warehouse of student and course information and is designed to accept progress and generate reports accurately so that any point of time any user can get the student information.

\section{ISSB's Vision of Student Information System}

- $\quad$ Provide better services to students, faculty, staff, prospective students, parents, etc.

- $\quad$ Provide meaningful, consistent, and timely data and information to end users

- $\quad$ Promote vision of senior management to address opportunities for change

- $\quad$ Update technology infrastructure for more effective and flexible delivery of new systems

- $\quad$ Promote efficiencies by converting paper processes to electronic form

- $\quad$ STUDENTSPACE applications are proven to reduce time spent on administrative tasks so you can concentrate on raising student achievement. It also facilitates networking of colleges/schools to University/Board, colleges/schools to society, colleges/schools to each other, provided they are equipped with his system. 


\section{Product Main features}

The main features of STUDENTSPACE are to support the maintenance of personal and study information relating to:

- $\quad$ Handling enquiries from prospective students

- $\quad$ Handling the admissions process

- $\quad$ Enrolling new students and storing teaching option choices

- Handling examinations, assessments, marks and grades, and academic progression

- $\quad$ Maintaining records of absences and attendance in e-classroom

- $\quad$ Handling Student Bursary requirement

- Handling award of credit or qualifications and graduation process

\section{EXHIBIT 4 - LEARNSPACE}

\section{LEARNSPACE - Think Freely}

Learning Management System, LEARNSPACE, in essence, is a high-level, strategic solution for planning, delivering, and managing most learning events within an organization, including online, virtual classroom, and instructor-led courses. The focus of LEARNSPACE is to manage learners, keeping track of their progress and performance across all types of training activities.

LEARNSPACE goes beyond conventional training records management and reporting. The value-add for LEARNSPACE is the extensive range of complementary functionality that it offers, such as; Learner Self-Service (e.g. self-registration on instructor-led training), Training Workflow (e.g. user notification, manager approval), the Provision of On-line Learning (e.g. Computer Based Training, Read \& Understand), On-line Assessment, Collaborative Learning (e.g. application sharing, discussion threads), and Training Resource Management (e.g. instructors, facilities, equipment).

LEARNSPACE is developed on Java 2 Enterprise Edition software platform and is web-based to facilitate "anytime, any place, any pace" access to learning content and administration.

The main features of LEARNSPACE include:

- $\quad$ Auto enrollment (enrolling learners in courses when required according to predefined criteria)

- $\quad$ Manager enrollment and approval

- $\quad$ Ability to create/suspend learner profiles

- $\quad$ Boolean definitions for prerequisites or equivalencies

- $\quad$ Integration with performance tracking and management systems

- $\quad$ Planning tools to identify skill gaps at departmental and individual level

- $\quad$ Support for Industry standards like SCORM 1.2 content packages and W3C standard for user interface design

- $\quad$ Curriculum, required and elective training requirements at an individual and organizational level

\section{EXHIBIT 5 - CONTENTSPACE}

\section{CONTENTSPACE - Pure Creativity}

The I-SYS Content Management System (CONTENTSPACE), provides primary management of the learning content used for the e-learning solution. CONTENTSPACE facilitates learning content management at a lower level of granularity, which allows organizations to more easily restructure and repurpose online content. CONTENTSPACE has emerged as the Content Management solution of choice because its state-of-the-art technology supported by professionals. CONTENTSPACE allows the creation of content by enabling good workflow processes - plan, design, develop, and integrate. 
CONTENTSPACE is a comprehensive solution for managing content as it empowers users to create, publish and manage content which is richly formatted, timely, accurate and personalized. With the help of easy-to-use tools for authoring and scheduling content, creating workflows and meta-tagging, the users will get just the information they need and the content manager will have the power to present the content as and when requested.

\section{Salient features of CONTENTSPACE}

- Superior customization and content generation

- $\quad$ Good database connectivity to create dynamic content quickly and easily

- $\quad$ Manage and update the latest content in order to address rapid changes

- Seamless integration of learning content into portals for use in learning management solutions and elearning

- $\quad$ Easy and flawless conversion of old content to easily usable media-rich digital content

- $\quad$ Ability to incorporate animation and graphics developed on latest media technology

- $\quad$ Ability to integrate enterprise content to ERP and CRM applications

- $\quad$ Sophisticated control of content access to content managers (create and maintain content) and users (view and use content)

- $\quad$ Ensure that content is properly reviewed and approved prior to publishing by using a multi-step, role-based workflow.

\section{EXHIBIT 6 - HIGH LEVEL ARCHITECTURE OF THRICE}

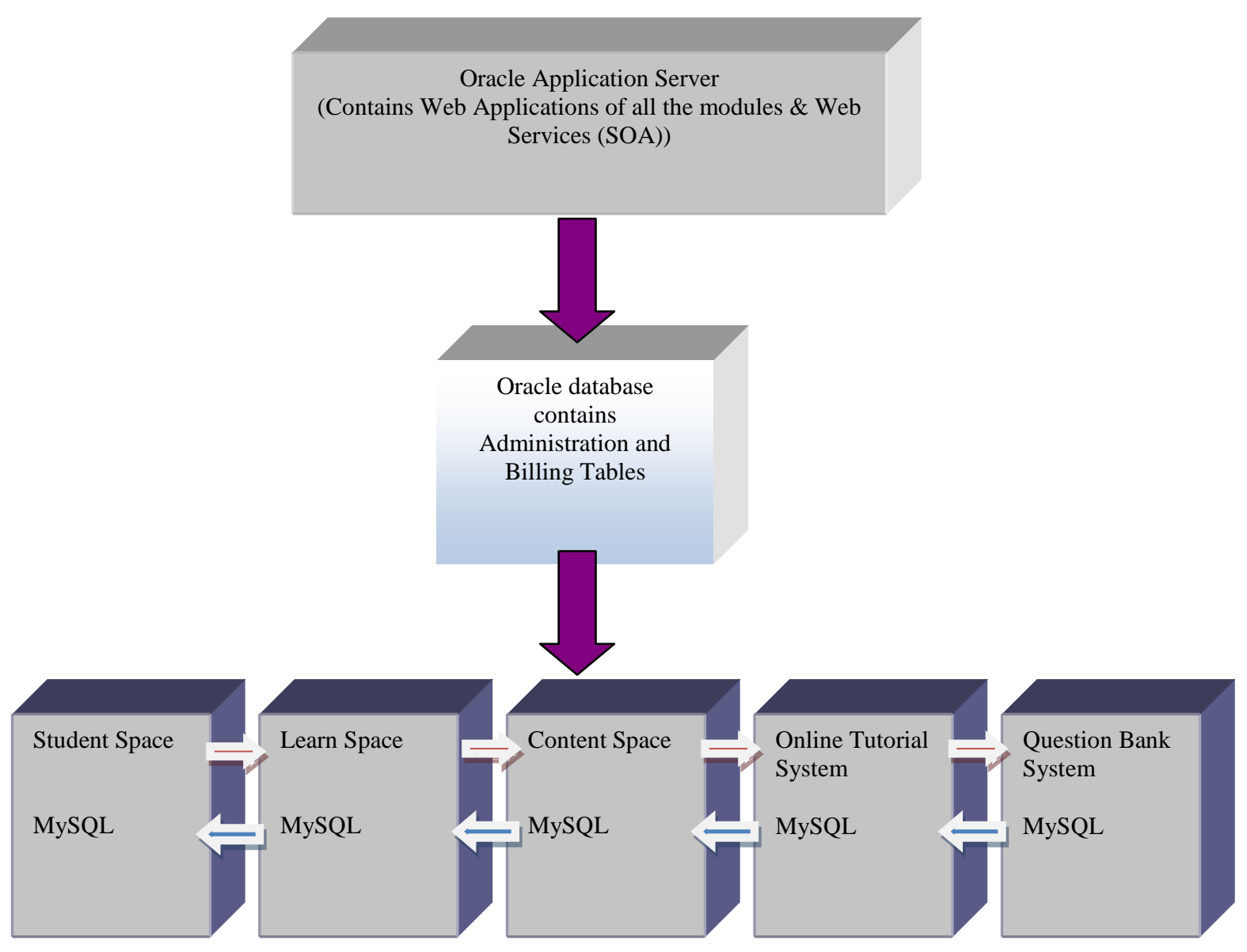




\section{NOTES}

